\title{
Alfonso XII y el turno sin pacto. Prerrogativa regia y práctica parlamentaria
}

\author{
Ángeles LARIO
}

\begin{abstract}
RESUMEN
ABSTRACT

Alfonso XII era un Rey considerado

Politics and analyst of his time, thought extremadamente liberal, él mismo se presentó como no creyente, y con la ambición de ser un Rey verdaderamente constitucional. La primera llegada de los Liberales, en 1881 , considerada tradicionalmente como el primer ejemplo de turno pacífico entre los partidos, fue fruto de

la decisión del Rey de cambiar de politica, después de seis años de Gobierno conservador. Cánovas, sin embargo, no habia encontrado todavia

el modo de proceder a un turno pacífico entre los partidos, que fue forzado por el monarca, y que obligó al jefe conservador a provocar la caída de ese Gobierno por todos los medios: no habia todavía mecanismo alguno

para hacer salir a un Gobierno del poder y se podia volver al exclusivismo. Alfonso XII was a very liberal King. He wrote thas he wasn't as much catholic as this ancestors. He wanted to be a true constitutional King. The first Government of Liberal Party, in 1881 , was a King's decision, after six years of Conservative Government. Cánovas was doubtful about wich way the crisis should be resolved, and he tried all posibilities for carry Sagasta out of power: The "pacto" still don't working.

\section{KEY WORDS}

Monarchical Restoration, politic crisis, Alfonso XII, peaceful turn, Kings'power, parliamentary practice.

PALABRAS CLAVE Restauración, crisis politica, Alfonso XII, turno, prerrogativa regia, práctica parlamentaria.
\end{abstract}




\section{ALFONSO XII Y SUS ANSIAS DE SER UN REY CONSTITUCIONAL}

Sagasta y los individuos del partido constitucional que comieron en $\mathrm{Pa}$ lacio en junio de 1875 salieron prendados de su entrevista con Alfonso XII y del arte que ponía el joven Rey en su conversación; de tal forma que fue Sagasta el que más extendió el criterio acerca de "la prontitud de ingenio, encanto de la palabra y condiciones atractivas del joven Monarca". El partido Constitucional, dirigido entonces por Sagasta, Topete y el duque de la Torre, desde el principio se había manifestado dispuesto a acatar la nueva situación creada por la Restauración. Ya el diario La lberia, uno de los órganos "autorizados por diferentes acuerdos de la Junta Directiva", y sobre todo "el único... que queda», había hecho declaraciones "explícitas y categóricas" de monarquismo, por lo que en expresión de Sagasta en mayo de 1875, nadie podía dudar de que uel partido en masa reconoce y acata la Monarquía Constitucional de D. Alfonso XII» ${ }^{1}$.

Pero ello no quiere decir que los Constitucionales entonces estuvieran especialmente predispuestos a una visión óptima del Rey; lo cierto es que en general las descripciones que nos han dejado de él son muy halagüeñas. Tanto en las del diplomático Conte como en las del embajador inglés, Layard, pasando como podemos ver por la de los futuros Liberales, se destacaba su inteligencia, su bondad, su amabilidad, además de sus felices ocurrencias, sin olvidar la falta de orgullo que, combinado, decía Layard, con la vanidad necesaria, lo hacian muy atractivo. Indudablemente poseía un carisma personal que lo hizo atractivo a todo aquel que lo conocía personalmente, como fue el caso de la mayoría de los embajadores extranjeros e incluso muchos de sus oponentes republicanos.

Pero lo que nos interesa destacar ahora es la idea generalizada que se tenía sobre sus tendencias liberales que alguno creyó que «lo avecinaban a los partidos revolucionarios"; eso se achacaba a su juventud y su entusiasmo por la popularidad ${ }^{2}$. Pero lo cierto es que también en sus anotaciones intimas mostraba una cierta liberalidad e independencia de pensamiento al mostrarse poco o nada creyente en la fe de sus mayores. Así puede leerse

\footnotetext{
Francisco Silvela, “Los partidos políticos", Nuestro Tiempo, mayo de 1902, n 17, suplemento. Archivo de Palacio (AP), 25/N, carta de SAGaSTA a Francisco Sastre, presidente del Comité Constitucional de Tánger, el 2 de mayo de 1875.

2 Public Record Office, Foreign Office (PRO.FO), 72/1412, informe de Layard a Derby de 25 de octubre de 1875. Archivio Segreto Vaticano, Segretaria di Stato (ASV.SS), 1885, 249.5, informe del Rampolla del 10 de mayo de 1885. Id para los informes alemanes en E. R. BECK, A time of triumph and of Sorrow. Spanish Politics durig the Reign of Alfonso XII. 1874-1885. Illinois, 1979, p. 195. J. Varela ORtega, Los amigos políticos. Partidos, elecciones y caciquismo en la Restauración. 1875-1900. Alianza, Madrid 1977, p. 120.
} 
con ocasión de la muerte de la Reina Mercedes que «me he quedado como un cuerpo sin alma, ... el único descanso moral es contemplar estas sierras tan ásperas o recorrer por este monasterio de San Lorenzo, los sombríos recuerdos de aquel Rey, que al menos tenía la suerte de ser creyente. Él hubiera creído que yo volvería a encontrar a Mercedes en el cielo" ${ }^{3}$.

Al lado de estas tendencias liberales hay que destacar sus ansias por ser un Rey verdaderamente constitucional, lo que le llevó a consultar al embajador inglés sobre los detalles de la política constitucional en Inglaterra, y particularmente la relación entre el Rey y los ministros, para conjugar el necesario respeto a la responsabilidad ministerial, que implicaba sin duda libertad de decisión, con la necesidad de conocer aquello que tenía que firmar todos los días y que al fin servía para legitimar la política de los Gobiernos, ya que éstos controlaban las mayorias parlamentarias de tal forma que no se podia esperar un control parlamentario de sus políticas, y en último extremo un castigo en las urnas por sus posibles errores.

En esta situación, el Rey acumulaba en la práctica una gran porción de responsabilidad, pues era la única institución capaz de provocar los cambios políticos, de tal forma que la permanencia de los Gobiernos significaba su confianza en ellos y su apoyo a la política llevada a cabo. Por eso se dijo desde las propias filas de los partidos del turno que el Rey, a falta de unas elecciones libres. era un «piloto sin brújula», que tenía que dirigir la nave del Estado sin una guía eficaz, que realmente le librara de todas las responsabilidades de sus decisiones.

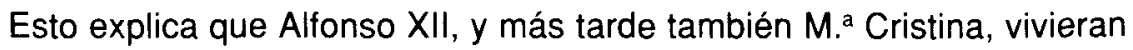
preocupados por la falta de moralidad en la vida política, y particularmente por el control que sobre las elecciones ejercían los Gobiernos.

Por ello Alfonso XII quiso intervenir más en la gobernación del país para no quedar prisionero de un partido o de un Gobierno, y exigió que se le hicieran conocer los temas que debía firmar, con la suficiente antelación para poder juzgar al respecto. Estaba dispuesto a ser plenamente constitucional, le decía al embajador inglés, pero también a imponer ese tipo de Gobierno en España, tal y como él lo había visto en Inglaterra, por lo que, sin enfrentarse a sus ministros, quiso conocer el medio que tendría para

3 Real Biblioteca de Palacio (RBP), Manuscritos, Il/4051, $n^{2} 15$, Diario de Caza de Alfonso XII; anotación de 31 de julio de 1878 (el subrayado no está en el original). Puede verse Ángeles LARIO, Monarquia Constitucional y Gobierno Parlamentario. El Rey en las crisis políticas (1875-1902), Tesis Doctoral, UNED, Madrid, 1997; pp. 113 y ss. En prensa: El Rey, piloto sin brújula. Monarquía Constitucional y Gobierno Parlamentario (1875-1902). Biblioteca Nueva. Id. “Alfonso XII. Católico y Liberal», en Historia 16 (en prensa) 
poder influir en el futuro político. Prudentemente, Layard, sujeto de la consulta efectuada por el Rey a este respecto, le contestó que actuara con prudencia, recordándole que el proceso inglés había supuesto muchos años de construcción, y no se podría implantar de golpe en otras esferas.

Pero el embajador sacó una conclusión de esta entrevista, grandemente favorable para el Rey pero poco esperanzadora para el régimen, y fue la de que su inteligencia y su capacidad estaban por encima de la media, que tenía una apropiada forma de expresarse que era inusual para su corta edad, pues no había cumplido los dieciocho años, pero sobre todo, que con estas características no podía contar con nadie a su lado con quien compartir sus juicios y ser guiado, inmersos como estaban los políticos en intrigas e intereses propios; lo que por cierto no desconocía Alfonso XII.

Su independencia de carácter la mostró pronto al asegurar que había "dos cosas en las que no he de ceder, aunque me vaya en ello la corona: suprimir la libertad religiosa y casarme contra mi voluntad". No se arredró a mantenerlo públicamente, con ocasión de una recepción de la Corte, en la que el Obispo de Salamanca le pidió protección para la Iglesia, a lo que le contestó el Rey que «en efecto, era preciso proteger a la Religión Católica, pero respetando la conciencia de todos". A consecuencia de lo cual Cánovas dijo en la intimidad, y no precisamente en tono positivo, que "tenemos un amo» ${ }^{4}$.

Con este panorama ha de sorprender menos que el propio Rey fuera consciente de la necesidad de llamar más pronto que tarde a Sagasta para cambiar el predominio de los Conservadores. Así lo manifestó en más de una ocasión, y sobre todo cuando Martínez Campos tuvo que dejar el poder en 1879.

\section{UN TURNO SIN PACTO}

Pero para Cánovas el problema estaba, no en llamar pronto al partido Constitucional, sino en el modo de hacerle salir del poder una vez que lo hubiera ocupado.

Hemos de tener en cuenta que Cánovas estaba intentando llevar a la práctica un Gobierno Parlamentario, con todo lo que ello significaba. Y que eso lo pretendía conseguir sin que las elecciones fueran el medio de

4 F. Silvel-A, "Los Partidos Políticos", cit. 
obtener una mayoría parlamentaria de la que el monarca simplemente tuviera que llamar a su jefe a gobernar. Por el contrario, se partía de una situación perfectamente contraria, en la que el Rey llamaba a gobernar al jefe de un partido que inmediatamente después estaba ya capacitado, una vez que ocupaba el ministerio de la Gobernación y todos los hilos de la Administración, para conseguirse una mayoría adecuada. Por lo tanto el Gobierno que entrara en esas condiciones debería dar una garantía de que no se iba a perpetuar en el poder. Debería existir por medio un pacto político que sin embargo Cánovas no consiguió hasta la muerte del Rey.

En esta coyuntura, Cánovas no veía ningún momento adecuado para provocar el turno, y tuvo que ser el propio Rey quien forzara la alternancia política, y lo hizo en un momento poco adecuado, cuando todavía no habían sido aprobados los presupuestos del año económico que empezaba en julio, y cuando ya no daba tiempo al nuevo Gobierno a aprobarlos; de tal modo que ese año los presupuestos fueron aprobados el 31 de diciembre, saliendo en la Gaceta el 1 de enero de 1882, sirviendo así también para el siguiente año económico, el de 1882-1883 (hasta comienzos del nuevo siglo no se asimiló el año económico al año natural, yendo aquél del 1 de julio al 30 de junio siguiente).

Esta circunstancia nos indica que todavía la práctica que luego será usual no estaba establecida aún. Más tarde se habló de las crisis a plazo fijo y preferentemente producidas después de haber sido aprobados los presupuestos del año económico que iba a empezar.

La postura de Cánovas quedó de manifiesto en su advertencia en el Congreso de que era necesaria «alguna regla, algún criterio» para solucionar las crisis, pues no se podían dejar al albur de las decisiones regias, como en los poco recomendables tiempos pasados del liberalismo español. Esto lo dijo en junio de 1880 , poco antes de producirse la primera alternancia política el 8 de febrero de 1881 .

Por eso cuando el cambio se produjo no quiso hacerse responsable, y no ocultó el origen de la crisis, que no era otro que el deseo de Alfonso XII de cambiar de Gobierno hacia una política más liberal.

Pero iba a ser esta crisis precisamente, por ser una crisis constitucional (en referencia al artículo 54.9 de la Constitución que establece la libertad del Rey para cambiar de ministros), la que iba a dejar sentado el medio por el cual un presidente podía salir del Gobierno dignamente aún a instancias del monarca. Este medio no era otro sino la presentación a la firma de un Real Decreto con alguna dificultad para que al plantear el Rey la necesidad de más información, el presidente pudiera ofrecer la posibilidad de abrir consultas y asi abrir el camino a un cambio político sin agravios entre las instituciones. 
Sin embargo, en esta primera ocasión, con un Rey todavía poco adiestrado en los pormenores de la política cotidiana, no se abrieron consultas, denunciando la carencia de acuerdo previo entre los partidos. En todo el proceso de esta crisis quedó demostrado que la llegada de Sagasta al poder no fue el inicio de un turno pacífico que en el futuro siempre necesitó de la fluidez que otorgaba la apertura de consultas, sino el turno sin más, iniciado a instancias del Rey.

Por si estos datos no fueran suficientes, hemos de señalar además que Cánovas, disgustado por el cariz que iban tomando las cosas, y en un intento de presionar para que no sucedieran así, luchó cuanto pudo amparado en su mayoría, enfrentando el poder de las Cortes al poder regio. Que Sagasta llegó contra su opinión lo demuestra también el hecho de que el nuevo Gobierno vivió en provisionalidad, sin Cortes ocho meses, y teniendo que servirse del proyecto económico aprobado para la anterior legislatura. $Y$ es que Cánovas decidió plantear la cuestión de confianza al Rey el mismo día que se iban a empezar a discutir en las Cortes los presupuestos del nuevo año económico: el 6 de febrero de 1881.

Hay que destacar que frente a lo que fue usual en la política del pacto, Cánovas no prestó su mayoria al nuevo Gobierno para aprobar con urgencia los presupuestos y ya después, una vez disueltas las Cortes proceder a una nueva elección. En este caso las Cortes fueron suspendidas el 9 de febrero y ya no se volvieron a reunir hasta el 20 de septiembre.

Pero en esta ocasión podemos apreciar por primera vez la utilización de un recurso que sorteaba la obligatoriedad constitucional de reunir Cortes a los tres meses de ser disueltas. Efectivamente la Constitución se cumplió, sólo que para darse más tiempo para preparar las elecciones y obtener una mayoría favorable, el Gobierno recurrió a la suspensión en lugar de la disolución. Ésta, como será usual, no se produjo hasta que el Gobierno se encontró en disposición de poder abrir las Cortes a los tres meses. Esta es la razón de que se disolvieran el 25 de junio, tres meses justos antes de reunirse las nuevas Cortes liberales. Con ello se ponía de manifiesto la práctica inutilidad del precepto constitucional establecido en el artículo 32 de la Constitución, sorteado con toda facilidad por el recurso a la suspensión.

Esta circunstancia no pasó sin críticas, y fueron precisamente los conservadores, en una demostración más de la falta de acuerdo para el cambio, quienes denunciaron el uso «hipócrita» de la Constitución. Los Fusionistas (así denominados desde su unión en 1880 con el Centro de Alonso Martínez y los Generales más prestigiosos de la Restauración que siguieron a Martínez Campos en su desgajamiento de Cánovas) se defendieron 
acusando a los Conservadores de no cumplir con sus obligaciones, al no haber aprobado antes el presupuesto, y por ello de abusar de la regia prerrogativa, que de no hacer caso omiso de esa situación se habría sentido presionada a permanecer siempre con el partido de Cánovas ${ }^{5}$.

\section{LOS LIBERALES Y LA PRERROGATIVA REGIA}

Sagasta dirigía el partido Constitucional desde que consiguió dejar de lado a Topete y el duque de la Torre que habian compartido con él la jefatura de los Constitucionales. Lo consiguió a raíz de uno de los conflictos que Martínez Campos solía crearle a Cánovas y que éste solucionó presentando al Rey la dimisión del Ministerio en caso de que Alfonso XII no resolviera a su favor; le pedía "una real resolución de V.M. comunicada por el ministro de la Guerra al General Martínez Campos ordenándole que conserve su puesto hasta la vuelta de V.M. a Madrid"; y es que Cánovas no estaba dispuesto, por dignidad, a mantener con Martínez Campos unas relaciones tal y como estaban planteadas, ejerciendo el General una presión constante sobre el ministerio para imponerse en sus exigencias, amparándose en lo que se le debía. Alfonso XII resolvió apoyando a Cánovas, diciéndole que "cualquiera que sean los servicios del expresado General y mi vivo deseo de mantenerlo en actividad... pueden V.E. y el Gobierno todo contar con mi completo apoyo y confianza».

El telegrama del Rey era del 27 de enero, y tan pronto como el 5 de febrero ya salía en la Gaceta un decreto del Gobierno limitando a los militares su participación en la política, como la manifestación más clara del triunfo del poder civil sobre el militar, sobre todo en lo más evidente como era la pretensión de imponer al Rey por encima del Consejo de Ministros en las resoluciones del Gobierno referente al Ejército. Fue precisamente en el Rey, como jefe del Ejército a la par que del poder Ejecutivo, en el que encontró el poder civil la fuente de su dignidad ${ }^{6}$.

Así es que poco después pudo decir Sagasta que «la alta gerarquía militar que ocupan mis compañeros, a quienes tanto debe el partido y la nación, les impide mezclarse en los graves asuntos políticos pendientes hoy", erigiéndose él como jefe único del partido ${ }^{7}$.

\footnotetext{
5 Romero Robledo el 5 de octubre de 1881, y, NavarRo y Rodrigo el 8 de noviembre: Diario de Sesiones del Congreso (DSC), leg. 1881-1882, t.I y II.

Los telegramas de Cánovas al Rey, de enero de 1875 y el del Rey del 27, en AP, 25/E, 1 y 2. AP, 25/N, carta cit. de SAGASTA del 2 de mayo de 1875.
} 
Pues bien, desde al menos 1878 , cuando ya los Conservadores llevaban más de tres años en el poder, y dos desde que la Constitución había sido aprobada, y habiéndose aprobado ese año una nueva ley electoral que implantaba el sufragio restringido, Sagasta estaba esperando ser llamado a gobernar. Hay que tener en cuenta que en 1879 se cumplían tres años de vida de las nuevas Cortes, y se planteó el dilema de si debian dar por concluida su vida legal, según la normativa por la que fueron elegidas, la ley de 1870 , o se les debía aplicar la posterior Constitución que establecía cinco años de vida legal.

En este contexto parecía llegado el momento más oportuno para el cambio político, máxime cuando, después de acabada la guerra colonial, los representantes cubanos estaban esperando a ocupar sus asientos tras unas nuevas elecciones.

Pero Cánovas no estaba dispuesto a dar paso todavía a los Liberales, por lo que ya hemos apuntado de falta de criterios para los cambios políticos que le garantizara que Sagasta iba a dejar el poder en el momento oportuno; él no lo dijo tan claro en estos momentos, sino que alegó que "la dinastía» debía estar "firmemente asentada en el trono", lo que era lo mismo que desconfiar de la política que fueran a llevar a cabo los nuevos inquilinos de los Ministerios.

Pero para Sagasta el camino ya parecia largo y su partido amenazaba con la revolución si es que estaban condenados a la exclusión. Ésta se pondría de manifiesto si Cánovas se atrevía a presidir otras elecciones. Por si acaso, además de amenazar y abstenerse de ir a las Cortes denunciando que permanecian los obstáculos tradicionales, utilizaron la posibilidad de Posada Herrera y el grupo Centralista ${ }^{8}$.

Pero todavía no les había llegado la ocasión y Martínez Campos vino a ejercer el papel de Gobierno puente para Cánovas, aunque no le resultó fácil ni sin consecuencias esta etapa, en la que, por cierto, se frustraron las promesas para Cuba hechas en la paz de Zanjón, por la falta de apoyo de las Cortes conservadores a los proyectos del General.

En las elecciones llevadas a cabo por este Gobierno ya se procuró llevar a las Cortes una oposición Liberal (las elecciones las había dejado preparadas Cánovas) lo más blanda posible, en la idea de que el turno era inevitable, y por el peligro que representaba el acuerdo electoral a que habían llegado los Constitucionales y los Demócratas Progresistas de Martos

8 LOs detalles pueden verse en LARIO, Monarquia Constitucional y Gobierno Parlamentario. EI Rey en las crisis politicas (1875-1902), Tesis doctoral, UNED, Madrid 1997; pp. 129 y ss. 
con los Posibilistas de Castelar. El medio para conseguir la oposición más adecuada fueron los diputados cuneros, siempre más manejables que los que tenían fuerte arraigo en los distritos: era el "caciquismo artificial» del que se culpó a Cánovas a finales de siglo; de nuevo Silvela, precisamente entonces ministro de la Gobernación advirtió que la formación de la oposición Liberal "se hizo... con algún lujo de arbitrariedad y cierto empeño de imprimir con demasiada ostentación el sello de fábrica gubernamental de los electos, celebrándose mucho por entonces a los que se llamaron cuneros de oposición, como arte positivo para asegurar un caudal de adversarios, a la par nutrido y menos vigoroso y ofensivo, que los diputados con arraigo en sus distritos y firme convicción de su independencia de origen»? .

La salida de Martínez Campos del Gobierno frente a los deseos del Rey y con las promesas hechas en Zanjón incumplidas, aunque no por su culpa, le llevaron hasta el partido de Sagasta, y dieron pie a que el Rey, que ya en diciembre de 1879 intentó por dos veces una solución distinta a la Conservadora, se decidiera a llamar a un partido del que ya no le podian presentar argumentos de peligro para el trono, una vez que se le habían sumado el Centro de Alonso Martínez y los Generales más relevantes de la Restauración.

Por su parte los ya Fusionistas, una vez que advirtieron los intentos fallidos del Rey de salir de los Conservadores comenzaron a levantar la voz en favor de la libertad de la regia prerrogativa, considerando que la Monarquía sería la única que podría desatar los lazos de lo que se dio en llamar dictadura ministerial. La acusación de tener secuestrada la prerrogativa regia, de enfrentarse el Gobierno al Rey, abundó a partir de este momento, y el nuevo Gobierno de Cánovas se inauguró con una votación para una moción de confianza que el presidente pidió al Congreso y que como era previsible ganó con 201 votos (aunque tras las elecciones había 318 ministeriales); de esta forma Cánovas pudo presentarle al Rey su propia fuerza parlamentaria, como contestación a las dudas que había mostrado reiteradamente antes de volverle a llamar.

Pero tras estas evidencias de enfrentamiento entre Rey y Gobierno, los Fusionistas pasaron a pedirle al Rey directamente el poder. Utilizaron ampliamente la acusación de secuestro del poder del Rey, de dictadura ministerial, se sintieron con capacidad para pedir directamente al monarca

9 Francisco SIL VelA, “Los Partidos Políticos", cit., p. 724; el subrayado no está en el original. La denuncia del "caciquismo artificial" en EL IMPARCIAL, 18 de febrero de 1899, que habla de un cambio en las características del «cacique» en favor de la fuerza del Gobierno. 
el poder, incluso en forma de proposición incidental en el Congreso poco después de haberse producido la fusión con la reunión en el Salón de Presupuestos del Congreso de 130 individuos. En la proposición pedian que el Congreso declarara que «el libre ejercicio de la prerrogativa regia consignada en el párrafo 9 del artículo 54 de la Constitución, es una garantía para la defensa de las instituciones» ${ }^{10}$.

Llegaron a pedir abiertamente la acción del Rey, a sabiendas de que aquello podría producir también un despotismo, pero preferían, dijeron el despotismo regio, menos humillante, "al despotismo ministerial, el peor y más repugnante de todos los despotismos". En esta petición se reclamaba la «regeneración del sistema parlamentario... la pureza del sistema representativo", que justificaría ampliamente la intervención regia frente al Gobierno. Igualmente reclamaban de la Monarquía igual favor para todos los partidos, pues no podían vivir sin la popularidad que ello les proporcionaba.

La reacción de Cánovas nuevamente fue atenerse a la teoría parlamentaria, que "no admite que por un punto general el monarca se separe de lo que le proponen los cuerpos colegisladores", por lo que seguidamente pasó a pedir nuevamente una votación de confianza, acudiendo a Capitanes Generales y las firmas más caracterizadas de los grandes de España, rivalizando en figuras importantes para su partido. Por ello el futuro ministro liberal de Gobernación, Venancio González, dijo que Cánovas había organizado «una verdadera barricada dentro del Parlamento contra la prerrogativa regia" 11 .

Cánovas se mostró contundente frente a las pretensiones del Rey y de Sagasta, y no dudó en enfrentar a los poderes del Rey con los de las Cortes, que pretendía sostener sin que afectara para nada a «la esencia de la Institución Real» ni al "libérrimo uso de sus prerrogativas». Era la constante tensión alimentada por Cánovas entre la teoría monárquica imprescindible y la práctica parlamentaria inevitable ${ }^{12}$.

A su vez Sagasta se mostraba ahora mejor equipado para llegar al poder. Primero por esa confianza en la actuación regia a su favor, después porque la alternativa era su alianza con la revolución, pues si bien se con-

SAGASTA en el Congreso el 14 de junio de 1880: DSC, leg. 1879-1880, t. IX.

1 Las palabras de Cánovas son del 15 de junio de 1880 en el Congreso: DSC, leg. 1879 1880 , 1 . IX. La votación de confianza fue pedida en el Senado por el conde de Casa-Galindo el 3 de junio: DSS, leg. cit. t. IV. Las palabras de Venancio GonzÁLEZ son del 9 de noviembre de 1881: DSC, leg. 1881-1882, t. II.

12 Puede verse A. LARIO, "La Corona en el proyecto canovista", en J. TUSELL y F. PORTERo (eds.), Antonio Cánovas y el sistema politico de la Restauración, Biblioteca Nueva, Madrid 1998. 
fesaban monárquicos, no tenían ningún apego personal a la dinastía; a ello se sumaba su unión con los militares descontentos. Por ello pesaba mucho más su amenaza de retraimiento en las elecciones municipales, a la par que los republicanos recuperaban sus esperanzas a tenor de la previsible división de los monárquicos. La única solución, lo dijo claro Navarro y Rodrigo el 11 de junio en el Congreso, era que Alfonso XII retirara su confianza a Cánovas; lo que fue apoyado por una ajustada alegación de Alonso Martínez destinada a justificar la actuación de la Corona en aquella coyuntura frente al Gobierno. Fue la frase de Sagasta quizá la más gráfica: «el único remedio es que el auxilio venga del Rey», advirtiendo ya, siete meses antes de su frase famosa que le hacía caer del lado de la libertad, que entre la monarquía que planteaba Pidal y la república, siempre elegiría la última.

Por todo ello pudo asegurar Navarro y Rodrigo que uno estaba cegado... el volcán de las revoluciones en nuestra infeliz Patria, y aunque no arrojaba lava todavía... humeaba ya" ${ }^{13}$.

\section{CÁNOVAS Y LA PRÁCTICA PARLAMENTARIA}

Fue precisamente en esta coyuntura cuando Cánovas se vio obligado a pedir unas normas de actuación para la Corona.

No en vano los militares que apoyaban a Sagasta advertían al Rey por boca del más significados de ellos, el General Martínez Campos, de "gravísimos peligros de la continuación del gabinete Cánovas", mientras Valmaseda por fin se encargó de «dar a conocer al Rey la impaciencia de los militares liberales". Por eso ya en estas fechas se habló de la reincorporación del elemento militar como fuente del poder político.

Alfonso XII, manifestando todavía el incompleto funcionamiento de las premisas del Gobierno Parlamentario en una Monarquía Constitucional ${ }^{14}$, se entrevistó con Martínez Campos individualmente y en compañía de Sagasta antes y después de llegarse a la fusión liberal, por lo que tuvo la garantía de disponer de un sustituto para Cánovas cuando lo decidiera.

Cánovas acudió insistentemente a su mayoría parlamentaria que de nuevo se había manifestado al abrirse la legislatura de 1880-1881, en la

13 C. Navarro y Rodrigo, Un periodo de oposición, Madrid, 1886; pp. 378 y ss.

14 Puede verse A. LARIO, "La Corona en el Estado Liberal. Monarquia y Constitución en la España del $x \mid x$ ", en El Estado en España, Revista "Htistoria Contemporánea», $n^{2} 17$, Universidad del País Vasco, 1998. Un estudio más amplio en ld. Monarquía Constitucional y Gobierno Parlamentario... , cit., pp. 22-43; para la crisis en concreto 159 y ss. 
contestación al Mensaje de la Corona, el 1 de febrero de 1881. A ello añadía la necesidad de aprobar los presupuestos antes del 1 de julio, es decir del comienzo del año económico. Algunos diarios destacaron el afán repetitivo de la prensa conservadora, anotando que alguna había asegurado al menos cuatro veces que el Gobierno tenía la plena confianza regia ${ }^{15}$. Esta demostración del apoyo parlamentario era tanto más necesaria cuanto que de sus filas mismas salían voces tan significativas como la de Silvela (descontento también de la vida que Cánovas dio al Gobierno Martínez Campos) en favor de dejar actuar ya a la prerrogativa regia.

Pero precisamente este afán de mostrar una mayoría suficiente demostraba por sí mismo las dudas del Gobierno respecto a la confianza que en él tuviera depositada el Rey, lo que había quedado como evidencia pública en la recepción de Palacio del 23 de enero. La representación masiva de los Liberales unida a la actitud deferente del monarca hacia ellos, felicitando incluso a Alonso Martínez por su defensa en las Cortes de la prerrogativa regia, provocaron certidumbre de crisis.

Tampoco quiso Cánovas dar tregua en esta ocasión, y el presidente del Congreso, el conde de Toreno, aprovechando su tradicional felicitación a Alfonso XII por su santo, añadió apreciaciones políticas contra la actitud de los Liberales, en el mismo sentido que habían interpretado en el Congreso el voto de confianza referido cuando se votó la contestación al Mensaje de la Corona:

"no deben los que tienen abierto su palenque en las Cámaras y en la prensa, llevar las cuestiones contundentes de la política a determinadas regiones donde la contradicción está vedada y hasta el sencillo análisis puede llegar a los límites en que la severidad de la ley aparece".

En este mismo sentido se manifestó Cánovas con claridad: el Rey no debía dejarse llevar por «los rumores de los partidos», dándole a la regia prerrogativa casi un carácter sacerdotal y sagrado, para la que pedía aislamiento y soledad, sin duda denigrando de los contactos del Rey con la oposición y lo que eso iba a significar para la legitimidad y necesaria independencia de los Gobiernos ${ }^{16}$.

Por ello cuando se produjo la crisis Cánovas, aun dando facilidades para un proceso ordenado de la misma, no ocultó su origen, y la pre-

\footnotetext{
15 EL IMPARCIAL el 6 de febrero de 1881 es el que destaca este afán del diario La Politica.

16 Las palabras de Toreno recogidas por EL IMPARCIAL el 25 de enero de 1881 . Las palabras de Cánovas el 28 de enero en el Senado: DSS, leg. 1880-1881, t. II.
} 
sentó como lo que era, un desacuerdo entre el Rey y su Gobierno. Facilitó el proceso de la crisis al presentar un Real Decreto a modo de cuestión de confianza, requiriendo al Rey la confirmación de sus poderes para un periodo de tres años, que era el tiempo que decía necesitar el Gobierno para llevar a cabo el proyecto presentado por el ministro de Hacienda, Orovio - que por cierto no olvidó manifestar al monarca el apoyo parlamentario del que seguía gozando el ministerio-. Era un método que luego se admitió públicamente como el más adecuado para dar paso a estas "crisis constitucionales». En ella tuvo ocasión el Rey de plantear la inconveniencia de contraer ese compromiso a tan largo espacio de tiempo.

Ni siquiera fue Cánovas el que planteó esta cuestión de confianza al Rey, sino el mismo Orovio en su despacho cotidiano, acompañado de Romero Robledo y Duran y Lira. Y es que ya el día anterior el Rey habia manifestado sus dudas ante la prolongación del Gobierno, y Cánovas esa misma noche, tras su entrevista con él (aprovechando quizá el acontecimiento del concierto de piano que Rubinstein dio en Palacio), había comunicado la crisis al Gobierno y recogido sus cosas de Presidencia.

A partir de aqui Cánovas habló claro en las Cortes, mostrando al Rey los inconvenientes que provocaba la letra de la Constitución, pues al lado de la libertad de nombramiento de ministros establecía la irresponsabilidad del monarca y el necesario refrendo de sus acciones. Advirtió de su esfuerzo para hacer constitucional una crisis que surgía por expreso deseo del Rey «de organizar de otro modo el Ejecutivo», para lo que se valió del preámbulo al citado Decreto para darle una "ocasión legítima de justificar aquella crisis". Asimismo aclaró que callaron en principio el origen de la crisis "faltando a la costumbre de dar amplia cuenta al país de los motivos por que dejaron el poder", por no "decir aquí que tuvieron por conveniente poner a disposición del Rey sus cartera a fin de que S.M. pudiera constituir el Poder ejecutivo como mejor lo estimase" ${ }^{17}$.

Romero Robledo fue todavía más claro cuando dijo que "ya habíamos buscado la postura de caer", ante su inminente «despedida" del poder; término este último que dio lugar a una llamada de atención por parte del presidente de la Cámara, que se habia llenado de rumores ${ }^{18}$. 
LA TEORÍA MONÁRQUICA Y LA PRÁCTICA PARLAMENTARIA: LA APLICACIÓN DEL ARTICULO 54.9 DE LA CONSTITUCIÓN

El Rey resolvió llamar a Sagasta sin consultar previamente ni serle aconsejado por Cánovas, y los conservadores protestaron de la «despedida", que dijo Romero, no pactada y poco acorde con los objetivos de Cánovas para resolver las crisis; hay que tener en cuenta que además el relevo se produjo con una celeridad inusitada, pues en la misma tarde de ser planteada la crisis tenía formado Sagasta el Gobierno. Poco antes se había advertido que "conseguir el poder en tales circunstancias, derribar a un partido numeroso y fuerte, constituido en la más perfecta situación constitucional, sin que haya para ello causa alguna parlamentaria, sería, a pesar de la legalidad del acto, algo, y a juicio de algunos, no poco violento, y no podría calificarse de turno pacífico de los partidos" ${ }^{19}$.

Y esto era más así cuanto que Cánovas culpaba directamente a Martínez Campos del cambio político, tal y como le escribió a Duran -más cercano al General que al jefe conservador-: “A nadie le habrá pillado de susto ahí que el citado General deseaba hacer un cambio de política en sentido más liberal. Él lo ha aconsejado, y a él se ha atendido, cúlpese a quien deba culparse de haber traído la situación actual, y no se diga que la política conservadora es la causa de ella» ${ }^{20}$.

Curiosamente frente a la parafernalia que había precedido al relevo de Cánovas por Martínez Campos en 1879, el relevo por primera vez entre los partidos se hizo deprisa y corriendo, sin darle casi tiempo a los ministros a recoger sus cosas de los ministerios; de hecho el de Gracia y Justicia que había de refrendar el nombramiento al nuevo presidente llegó tarde a Palacio, lo que hizo demorar la Jura hasta las diez de la noche.

Cánovas puso en práctica en esta ocasión aun con notorio desapego y pocas ganas de cubrir por completo la responsabilidad regia, lo que se consideraba un uso admitido en "el régimen monárquico constitucional y parlamentario"; esto es, la rápida disposición que deben tener los presidentes del Gobierno a dar salida constitucional a los deseos del Rey en relación a su poder de nombrar los ministros: "tan pronto como se nota por hombres leales que ocupan el puesto de ministros responsables que la Corona vacila un tanto, que duda un tanto sobre si es conveniente que

19 LA ÉPOCA, 31 de enero de 1881.

20 Carta del 28 de junio de 1881 , recogida en la correspondencia de Duran publicada por B. de Riouer I Permanyer, Epistolari politic de Manuel Duran i Bas: correspondència entre 1866 i 1904. Abadia de Monserrat, Barcelona 1990; $n^{2} 109$. 
continúe una política o que la sustituya otra, esos hombres, por conciencia y por guardar debidamente la responsabilidad de la Corona, se anticipan, y ellos mismos provocan la crisis, porque ellos mismos la deben provocar»: no había que dejar que el Rey actuara fuera de las reglas admitidas, y siempre el presidente debía tomar la iniciativa material de la crisis ${ }^{21}$.

Fue en esta ocasión de extrema presión y tensión entre la Corona y las Cortes cuando Cánovas parece alumbrar lo que luego fueron las normas políticas admitidas para la solución de las crisis de Gobierno. Cuando Cánovas fue colocado por los Fusionistas en la posición de defensor del poder de las Cortes frente al de la Corona, se vio obligado a intentar un difícil equilibrio entre ambos poderes. Por ello reconoció que el uso que el Rey debía hacer de sus prerrogativas había de ajustarse a lo que se entendía que era un Poder Moderador. Su teórico poder no debía utilizarlo en su totalidad si realmente quería combinar la Monarquía con el sistema parlamentario. Por ello debía atenerse a las indicaciones de la opinión expresada mayoritariamente en las Cortes: el Rey podía legítimamente separar se ella, pero no debía. Entre otras cosas el Gobierno debía poder aprobar en las Cortes anualmente los presupuestos y la fijación de las Fuerzas del Ejército, lo que sería imposible de no tener una mayoría adicta, y el problema de gobernabilidad e inviabilidad consecuente de la Monarquía era evidente.

Ratificaba así el modelo de Monarquía de Gobierno Parlamentario ${ }^{22}$ en la que no se renunciaba teóricamente a todos los poderes regios que según los teóricos alemanes era la única garantía de las Monarquías, pero se advertía de la necesidad práctica de atenerse a los cánones del Gobierno Parlamentario, por vía de hecho, como tributo a las necesidades de los tiempos y medio de supervivencia y sentido actual de las Monarquías.

Es en esta coyuntura cuando Cánovas alude a lo que le sugiere la postura de los Liberales, como si acabara de caer en la cuenta de lo que podría suceder en las circunstancias en que se hallaba planteada la cuestión política. Los Liberales se habían hecho cargo rapidamente de la situación, utilizando la única vía posible para acceder al poder, dado el control de éste por los Conservadores y su decisión de utilizar todos los resortes administrativos para conseguir las mayorías adecuadas. Ante el recurso a la Corona, a la que los partidos habrían de quedar supeditados, Cánovas en

\footnotetext{
21 Canovas en el Congreso el 6 de mayo de 1891 en referencia a la crisis de 1881: DSC, leg. 1891, t. III.

22 Puede verse LARIO, "La Corona en el Estado Liberal...", cit., o ld. Monarquía Constitucional y Gobierno Parlamentario...”, cit., I capitulo.
} 
lugar de proponer como una posibilidad la necesidad de ir reformando los abusos electorales (que creía necesarios para la conformación de dos grandes partidos), atendió fundamentalmente al modo de controlar la prerrogativa regia, de normativizarla y darle criterios fijos, lejos del criterio personal que de imperar trocaria la Monarquía en un "despotismo oriental» (esta era la clasificación de Montesquieu, su diferenciación entre Monarquía y despotismo), y que ya bajo el reinado de Alfonso XIII se volvería a traer a colación en directa acusación de régimen personal, donde sólo el capricho presidia los cambios políticos (y no en referencia al Palacio Real, donde siempre se resolvían las crisis tanto por exigencias teóricas como prácticas. Por otra parte el término "oriental» para referirse al Palacio es más tardío, cuando bajo el franquismo se quería obviar tanto la calificativo de "real», como el de "nacional», como los republicanos habían denominado al Palacio) ${ }^{23}$.

Cánovas planteó la necesidad de que el Rey, para salvar su responsabilidad en los cambios de Gobierno, debía atenerse a «alguna regla, algún criterio". Estaba enunciando la necesidad de atenerse a unas normas que no estaban en ningún sitio escritas pero que aparecian como imprescindibles, pues de lo contrario, se pregunta, " ¿Es que el Monarca, para evitar la responsabilidad moral, que no puede negarse que hay en todos los actos humanos, ha de echar a la suerte la formación de los Ministerios?", por ello insiste, "¿Qué ha de hacer el Monarca en este caso?... ¿Cómo habrá de proceder el Monarca para ser constitucional en este sistema?". No le parecía lo más adecuado en aquellos momentos que el Rey decidiera «repartir temporalmente entre todos los partidos el gobierno, dándoles el poder a cada uno en una parte del año, o dando el poder a cada partido cada año o cada dos años, repartiéndolo con completa igualdad, háganlo bien o háganlo mal, puesto que ningún partido ha de reconocer que lo hace mal, sino que todos han de reconocer que lo hacen perfectamente..." ${ }^{24}$.

Lo cierto es que tras esta crisis, la Corona y sus funciones fue tema permanente de discusión política, de tal modo que algún demócrata llegó a la conclusión de que los monárquicos no estaban de acuerdo en "la manera de funcionar los poderes inamovibles e irresponsables» ${ }^{25}$; y es que mientras los partidos tuvieran que acceder al poder litigando políticamente

23 Agradezco esta referencia oral a M. Luisa López Vidriero, Directora de la Real Biblioteca del Palacio.

24 Canovas en el Congreso el 15 de junio de 1880: DSC, leg. 1789-1880, t. IX

25 Fue CaRVAJaL en el Congreso el 3 de noviembre de 1881: DSC, leg. 1881-1882, t. II. 
hasta el fin, bien probablemente habían de utilizar todas las posibilidades de acceso, y a falta de poder parlamentario independiente era el recurso al Rey el más eficaz de todos. Por ello se acusaban mutuamente de "falsear por completo todo el régimen constitucional», disputándose un mayor y mejor amor al Trono, para cuya defensa cada uno tenía su receta particular, pasando a ser la base de la legitimidad de cualquier Gobierno el hecho de que sirviera mejor a la defensa de la Corona.

Y es que lo que temían los unos de ese poder monárquico cuando lo utilizaban los otros, era la falta de control en la práctica de los poderes constitucionales de la Corona, lo que Romero Robledo, una vez más, expuso claramente al decir que "cualesquiera que sean las instituciones que rijan, es seguro que para el cambio de poder han de encontrarse en todos los partidos auxiliares voluntarios y hasta entusiasmados que se presten a todo, aún a vulnerar la ley en todas sus partes". Y es que estaba acusando a los Liberales de inventar una Monarquía sin contrapesos, por lo que de cara al futuro sostuvo "y sostendré que hay pocas crisis más funestas que la del 8 de febrero", calificando el encargo del Rey como de "gravísimo mandato» ${ }^{26}$.

Los Liberales, sin embargo, también tenían un argumento de peso, y era el de que la Monarquía era la más alta intérprete de la opinión, máxime en las circunstancias en que el régimen parlamentario se desarrollaba en España, y que por lo tanto tenía "una responsabilidad moral ineludible ante la opinión" que la obligaba a actuar en el sentido en que lo hizo. A lo que añadía Sardoal el hecho incontestable de que "si esperaba (Cánovas) para entregar el poder a otros hombres que la opinión pública se manifestase por medio de los comicios, S.S. viviría eternamente en el banco azul»» ${ }^{27}$.

Para Martos no pasó desapercibida esta discrepancia de fondo entre los monárquicos y señaló el peligro en que éstos estaban poniendo a la Monarquía por querer vivir sólo de ella sin atender a los medios para favorecer la representación de la opinión pública en las Cortes, señalando certeramente que "cuando no funciona más que uno (organismo político)... aquel organismo funciona a costa de sí mismo... el remedio es otro... porque el mal está en otra parte", señalando directamente a los Liberales al preguntarles: "qué habéis hecho vosotros en materia electoral?», y po-

26 ROMERO ROBLEDo en el Congreso el 5 de octubre y el 7 de noviembre: DSC, leg. 1881 . 1882, t. 1 y II.

27 La cita sobre la responsabilidad moral es de Venancio GONZÁLEZ, ministro de la Gobernación, el 9 de noviembre de 1881. También AGULLRA el 10 de noviembre. Las palabras de SARDOAL el mismo día 10: DSC, leg. 1881-1882, t. II. 
niendo sobre el tapete el fondo de la cuestión que se estaba discutiendo y que originaba las divergencias entre los monárquicos ${ }^{28}$.

Cánovas aprovechó para advertir del peligro de la responsabilidad moral e histórica que la Monarquía iría acumulando si se atenía a la pura teoría constitucional. Finalmente el pacto entre los partidos a la muerte de Alfonso XII buscó una salida a la difícil situación de la Monarquía en este régimen ${ }^{29}$.

MARTos el 10 de noviembre de 1881 en el Congreso: DSC, leg. 1881-1882, t. II.

Puede verse A. LARIO, “La muerte de Alfonso XII y la configuración de la práctica política de la Restauración", en La España de Alfonso XIII. 1902-1931; separata de la Revista Espacio, Tiempo y Forma, serie V, t. 6, UNED, Madrid, 1993. 